\title{
A survey of South African Maxillofacial \& Oral Surgeon opinions regarding the academic education in the field of cleft lip/palate and craniofacial deformities
}

SADJ June 2020, Vol. 75 No. 5 p247 - p252

E Ghabrial ${ }^{1}$, KW Bütow ${ }^{2}$

\begin{abstract}
Background

Maxillofacial and oral surgeons (MFOS) are trained to manage hard and soft tissue conditions affecting the orofacial region. They, therefore, play an essential role in the health care of cleft lip/palate (CLP) and craniofacial deformities (CFD) patients.
\end{abstract}

The complex and lengthy nature of CLP and CFD management requires collaboration between different disciplines. Consequently, it becomes increasingly important that the academic education available to MFOS provides in-depth knowledge, multidisciplinary participation and adequate clinical exposure provided by field experts.

\section{Objectives}

This study aimed to investigate the exposure and knowledge level of MFOS regarding the management of CLP and CFD. A second objective was to obtain an opinion from practising MFOS about the academic educational needs of those working with CLP and CFD.

\section{Method}

An online survey and telephone interviews (using a structured questionnaire) were used to investigate the level and scope of the MFOS academic education and to determine their academic needs.

\section{Author affiliations:}

1. Emad Ghabrial: BDS HDD PG Dip MChD (Ortho), Senior Lecturer, University of Pretoria, Attending orthodontist for the Cleft Lip and Palate Clinic, Pretoria, South Africa.

ORCID Number: 0000-0002-7213-9760

2. Kurt W Bütow: MChD (MFOSurg), DrMedDent PhD DSc (Odont) FCMFOS, FIBCSOMS, Professor and Head of Department Emeritus, and former Head of the Cleft Lip and Palate Clinic, University of Pretoria, Pretoria, South Africa.

Corresponding author: Emad Ghabrial

Professor and Head of Department Emeritus, and former Head of the

Cleft Lip and Palate Clinic, University of Pretoria, Pretoria, South Africa,

PO Box 11654, Queenswood 0121

Email: emad.ghabrial@up.ac.za

Author contributions:

1. Emad Ghabrial: First author - $70 \%$

2. Kurt W Bütow: Second author $-30 \%$
Results

The questionnaire was completed by 53 (of 121) of practising MFOS on the Medpages health care provider database, $64.8 \%$ of whom had more than 10 years of professional experience.

Of the respondents, $60 \%$ showed a good general knowledge of CLP and CFD. However, 66.5\% acknowledged that they had received only limited clinical training and exposure, which prevented them from providing adequate services to CLP/CFD patients. Only $41 \%$ of the respondents offered primary and/or only secondary treatment for both CLP and CFD patients, and $53.8 \%$ of them had participated in multidisciplinary teams.

All the respondents agreed on the need for a dedicated training programme(s) in CLP and CFD management, and the majority recommended a subspecialty training either by degree courses or clinical fellowship and / or certification.

\section{Conclusion}

This study demonstrates that postgraduate academic training and clinical exposure are limited in the CLP and CFD fields. All the respondents agreed that an educational strategy to meet the needs of MFOS providing CLP and CFD care should be established. Participants suggested that part-time clinical and/or degree courses should be developed.

\section{Keywords}

Maxillofacial \& oral surgeon, cleft lip and palate, cleft lip, alveolus and palate, multidisciplinary, education, survey for dental professions.

\section{INTRODUCTION}

Surgical care for cleft lip/palate and craniofacial deformities (CLP and CFD) contributes to the global cost of disease, making many patients unable to access adequate surgical care. ${ }^{1}$ A shortage of human resources for surgical care, and inadequate surgical capacity and finance in developing countries (including South Africa), have been reported in the literature. ${ }^{2}$ 
Consequently, CLP and CFD surgery has been identified as one of the essential surgeries that need to be performed consistently around the world. ${ }^{3}$ The maxillofacial and oral 'surgeon's (MFOS) role is essential in caring for children born with CLP and CFD deformities. ${ }^{4}$

These surgeons are trained to manage both hard and soft tissue conditions affecting the orofacial region in order to achieve optimal functionality and aesthetically pleasing outcomes ${ }^{5}$ and to avoid midfacial dysgnathia as far as possible. ${ }^{6}$ Consequently, dental professionals prefer that MFOS manage CLP and CFD deformities. ${ }^{7}$

For many years, researchers and practitioners have understood the need to gain educational and clinical experience of treating all segments of society in order to provide quality management and improved access to care for all patients. ${ }^{8}$ One of the earliest attempts to assess the exposure of medical and dental students to CLP treatment was done by Lass et al. ${ }^{9}$ using a survey questionnaire. The main finding was that students lacked clinical exposure and basic theoretic education. ${ }^{9}$ Spriestersbach et al. ${ }^{10}$ acknowledge the effects of limited training in CLP management and advise that a clinician with limited training should not manage individuals with CLP.

These patients normally have challenging health issues because of additional complexities related to their skeletal, soft tissue and facial problems. This makes it more difficult to handle such patients as a single discipline cannot make all treatment decisions. ${ }^{11}$

Close collaboration between different disciplines is an integral part of the multidisciplinary team approach for the management of patients and has been advocated by practitioners. ${ }^{12}$ Therefore, practitioners involved in CLP and CFD should be educated not only in their own fields but also in the treatment provided by other disciplines involved in multidisciplinary care. ${ }^{13}$

As a result, the training and development of an efficient multidisciplinary team member should be based on a pedagogical model for successful skills transfer and cooperation within the team model. ${ }^{14}$ Not only is academic education essential for a multidisciplinary team member, but it must be combined with research in order to monitor and improve treatment outcomes. ${ }^{15}$

The value of treatment management relies on the training and exposure which the student received at university and the knowledge gained throughout the practitioner's career. Subsequently, feedback on the education rceived, and further training needs is necessary to provide a foundation for the improvement of educational courses, which will lead to the provision of better health services. ${ }^{16}$

\section{OBJECTIVES}

1. Measure the exposure and knowledge level of MFOS in the management of CPD and CFD.

2. Obtain an opinion from MFOS about the current CLP and CFD academic educational needs.

\section{METHOD}

Ethical permission was obtained from the Humanities and Social Sciences Research Ethics Committee reference (HSS/0235/017D), of the University of KwaZulu-Natal. The research survey was completed by South African MFOS who consented to participate in the study, using an online questionnaire to investigate the academic education provided to CLP and CFD practitioners.

A quantitative research method, using a 51-item structured questionnaire, was developed. Qualtrics Research Suite survey software was used to capture and analyse the data. The questionnaire was designed to collect quantitative data using a Likert-type scale, which was explained telephonically to each practitioner.

Consent for participation was obtained from each respondent prior to their completing the questionnaire. The data was collected either online or during a telephone interview, according to the preference of the participant.

\section{Questionnaire design}

The questionnaire consisted of a statement of consent to participate, followed by four sections: the first determined whether the participants were accepted for inclusion in the study. The second section collected their level of knowledge and experience. In the third section, their needs and preferences regarding further education were determined. The last section collected demographic data, which included a title, gender, age, degree(s) and location by region.

\section{Selection of participants}

A random sample of MFOS was obtained from the Medpages active practitioners' database list. ${ }^{17}$ The sample was randomly selected from the list using Microsoft Excel (2013). On the advice of a statistician, the number of participants selected represented all MFOS in South Africa, with a sampling error of approximately $15 \%$.

Before distribution, the questionnaire was piloted by a convenience sample of practitioners and subsequently revised based on their responses in order to ensure appropriate capturing of data. The researcher then approached the South African Society of Maxillofacial and Oral Surgeons to distribute the survey by e-mail. Initially, the questionnaires were to be distributed by the Qualtrics online survey platform twice during the first week, then weekly afterwards. This was ultimately not necessary, as the targeted participant number was achieved by randomly contacting 56 MFOS on the Medpages database.

\section{Data analysis}

The data was captured using Excel 2013. This was later converted into Stata 15 format. The analysis undertaken was descriptive summary statistics presenting frequencies and associated percentages. No further analytical tools were used because no hypothesis was being tested. 


\section{RESULTS}

The questionnaire was completed by $46.3 \%(n=53)$ of the MFOS practitioners listed in the Medpages database, representing most South Africa provinces, with the highest participation from Gauteng (44.2\%), Western Cape (19.2\%), KwaZulu-Natal (17.3\%) and Eastern Cape (7.6\%) (Fig. 1).

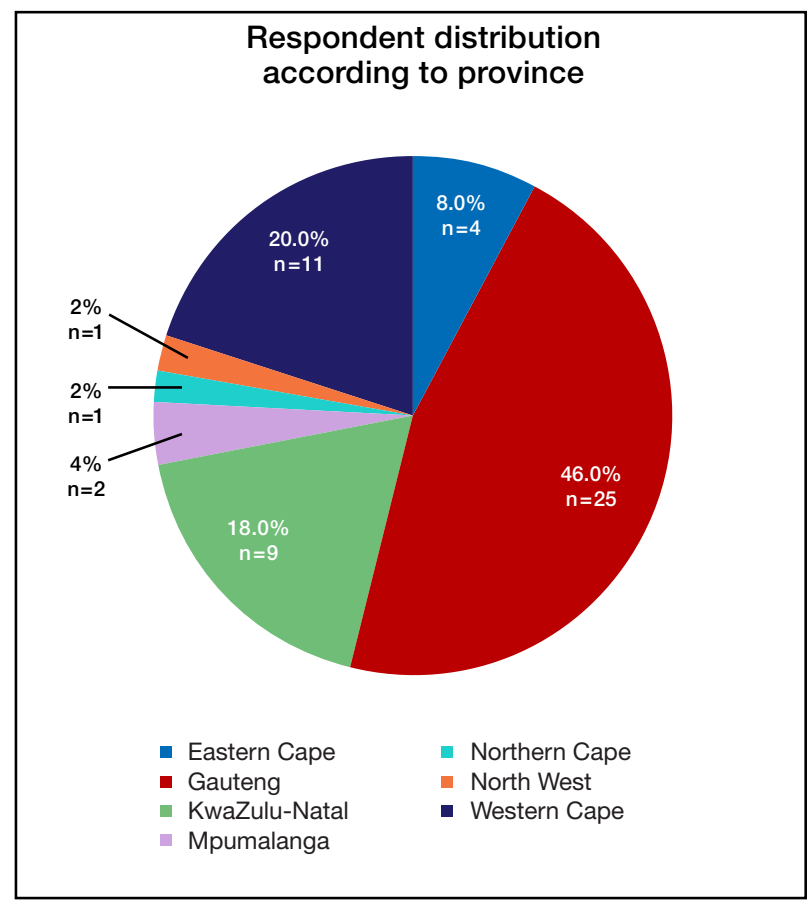

Figure 1. Respondent distribution according to province.

The distribution of participants according to years of experience showed that $64.8 \%$ had more than 10 years, 20.3\% had 5-10 years and the rest had less than five years of professional experience (Fig. 2).

When asked general questions about the incidence and distribution of CLP, only $62 \%$ showed good general knowledge.

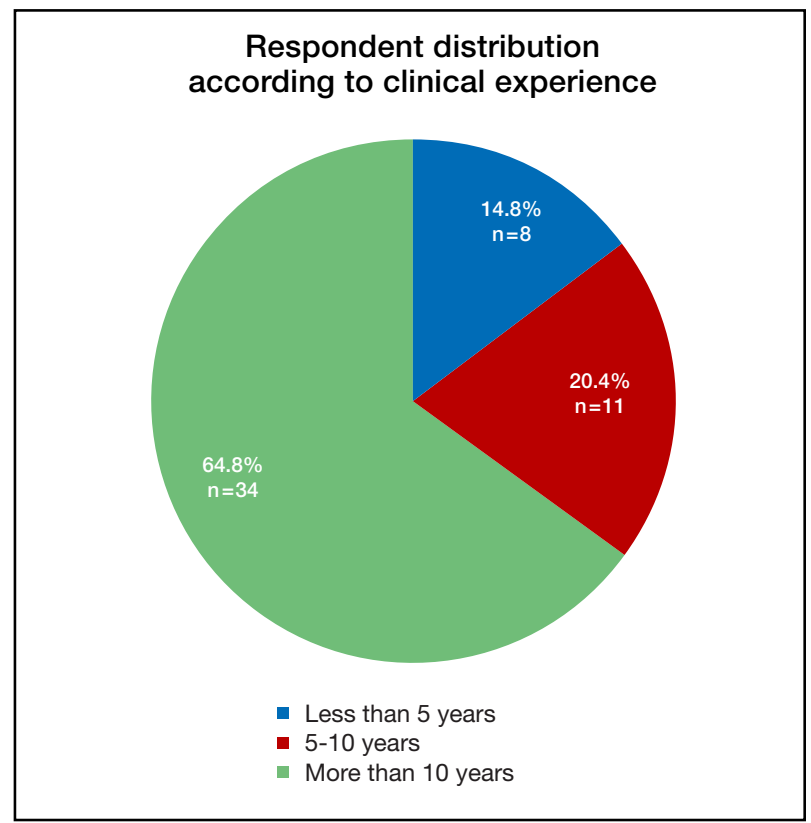

Figure 1. Respondent distribution according to clinical experience.
Regarding CLP/CFD academic education, the participants noted that, during their postgraduate studies, $38.8 \%$ had received some clinical exposure, and $40.7 \%$ had participated in CLP/CFD multidisciplinary and discussion meetings. A total of $61.1 \%$ gained their knowledge from textbooks, and $57.4 \%$ received their information by means of lectures (didactic input) (Fig. 3).

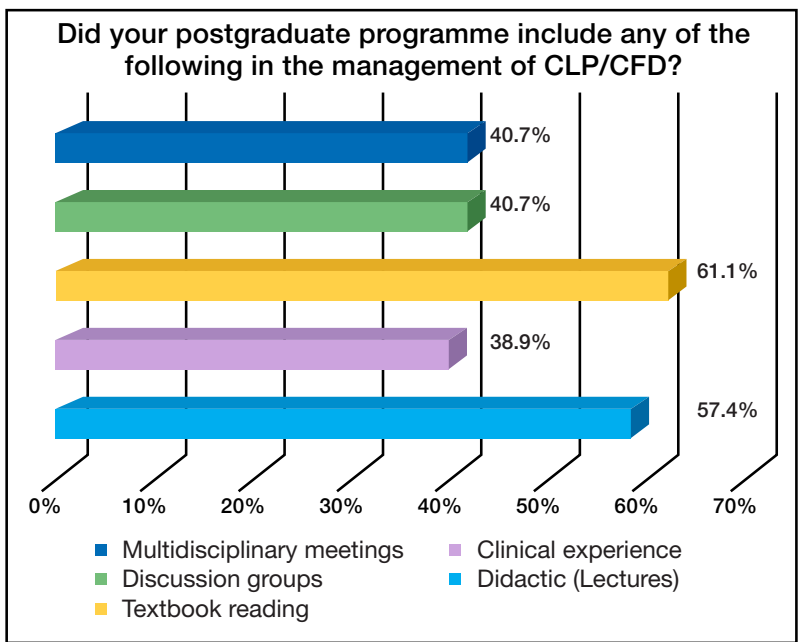

Figure 3. Did your postgraduate programme include any of the following in the management of CLP/CFD?.

Concerning services to CLP/CFD patients, $57.4 \%$ of the professionals did not offer surgical treatment for CLP or CFD patients. When asked to name the factors which prevented them from treating CLP and CFD patients, $66.7 \%$ acknowledged that it was due to their limited clinical experience and training, $12.5 \%$ mentioned the long duration of the treatment, $10.4 \%$ cited lack of interest, and $10.4 \%$ mentioned the need for multidisciplinary treatment (Fig. 4).

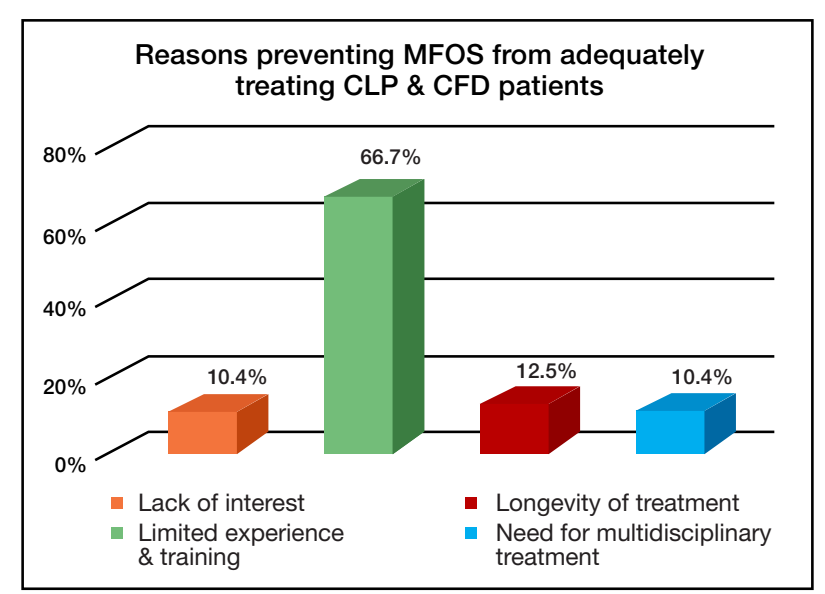

Figure 4. Reasons preventing MFOS from adequately treating CLP and CFD patients.

All the respondents agreed on the need for dedicated academic training programmes for CLP/CFD management. Of the respondents, $42.1 \%$ suggested degree (certification) courses, while $36.8 \%$ proposed non-degree clinical fellowships and the rest recommended continuing professional education (Table 1).

For degree and non-degree postgraduate CLP/CFD courses, the respondents suggested that admission requirements should include at least one professional degree. 


\begin{tabular}{|c|c|c|}
\hline Course recommended & $\%$ & $\mathbf{N}$ \\
\hline $\begin{array}{l}\text { Degree course, diploma, master's } \\
\text { and fellowship certification }\end{array}$ & $42.1 \%$ & 31 \\
\hline Non-degree course fellowship training (only) & $36.8 \%$ & 28 \\
\hline CPD courses & $21.0 \%$ & 16 \\
\hline
\end{tabular}

A total of $85.2 \%$ said that health professional full registration as a specialist was essential, whereas $44.4 \%$ placed emphasis on years of clinical experience and $22.2 \%$ suggested writing an admission examination (Fig. 5).

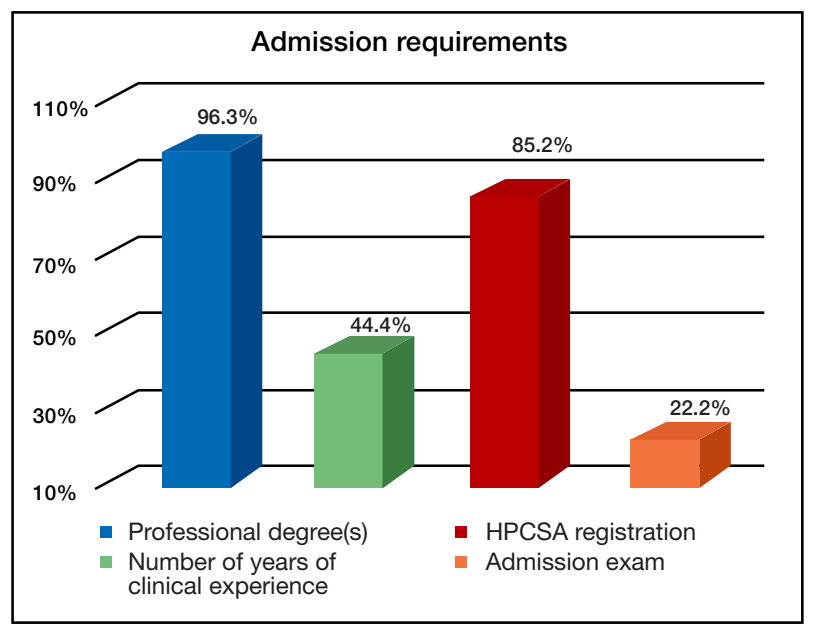

Figure 5. Admission requirements.

When the participants were asked about their motives for enrolling in such a programme, $46.2 \%$ identified interest and passion, $20.1 \%$ liked the idea of joining a multidisciplinary team, $14.8 \%$ mentioned alleviating community needs, $12.4 \%$ wished to receive a degree, and only $5.9 \%$ wished to improve their income (Fig. 6).

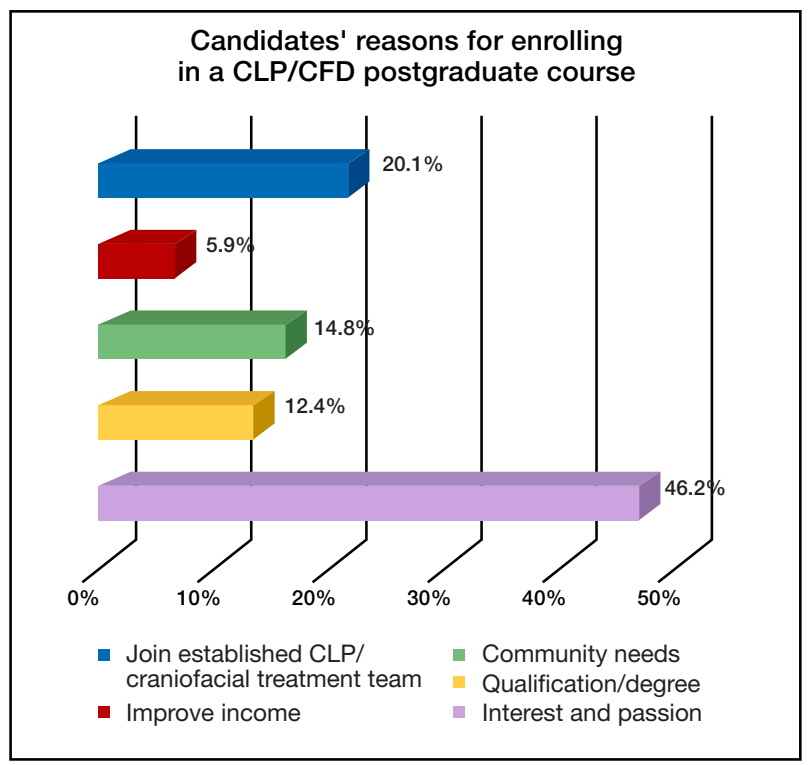

Figure 6. Candidates' reasons for enrolling in a CLP/CFD postgraduate course.

The participants had various views regarding the essential aspects of the goals and objectives of training programmes, but the majority agreed that diagnosis and treatment planning, clinical skills and multidisciplinary exposure are important.
Teamwork skills were valued by $79.6 \%$, whereas $68.5 \%$ proposed special needs care, $44.4 \%$ recommended some research experience and $31.5 \%$ suggested participation in charity missions (Table 2).

\begin{tabular}{lc} 
Table 2. The goals and objectives of postgraduate training programmes. \\
Goal \& objectives & $\%$ \\
\hline In-depth knowledge & $98.1 \%$ \\
\hline Diagnosis and treatment planning & $100.0 \%$ \\
\hline Clinical skills & $98.1 \%$ \\
\hline Multidisciplinary approach & $88.9 \%$ \\
\hline Research & $44.4 \%$ \\
Special needs care & $68.5 \%$ \\
\hline Teamwork skills & $79.6 \%$ \\
\hline Participation in charity missions & $31.5 \%$
\end{tabular}

Regarding the form of evaluation, $88.8 \%$ recommended keeping a logbook of clinical hours, $79.6 \%$ suggested a written/oral examination, $49 \%$ suggested assignments and $29.6 \%$ proposed publication in a scientific journal as an important evaluation method (Fig. 7).

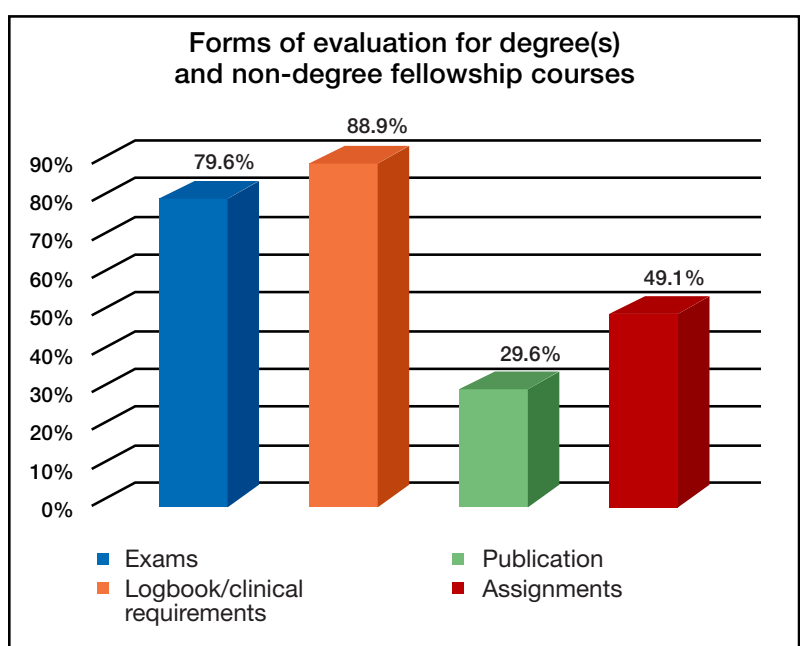

Figure 7. Forms of evaluation for degree(s) and non-degree fellowship courses.

\section{DISCUSSION}

To our knowledge, no survey has been undertaken in South Africa to investigate the opinion of MFOS about academic education in the field of CLP/CFD. However, such surveys have been conducted among other specialities in other parts of the world. ${ }^{9,18}$

Other surveys studies, of health professionals, used samples from the national bodies similar to the Health Professional Council of South Africa database. ${ }^{19,20}$ In this study, participants were obtained from a list of active MFOS practitioners in a privately managed Medpages healthcare database, which is regularly updated..$^{17}$ The sample was randomly selected from the Medpages list and included practitioners from different locations and places of employment, in order to overcome limitations and to obtain general opinions from all clinicians.

It is recognised in the literature that it is difficult to receive adequate response rates in surveys of medical practitioners. ${ }^{21}$ Some researchers have used e-mail, or postal questionnaires and others have used incentives to im- 
prove the response rate. ${ }^{22}$ In this study, the $46.3 \%$ response rate was achieved by using a mixed method of data collection using both telephone interviews and e-mail, which provided a wide distribution not limited by e-mail access, in line with recommendations by Flanigan et al. $^{23}$

Regarding the sample size the author used the literature information as a guide for an acceptable response rate. ${ }^{19,25}$ In agreement with the findings of other disciplines in regard to CLP/CFD academic education ${ }^{26,27}$, this study found a limited emphasis on clinical training and multidisciplinary exposure during academic graduate programmes, meaning that graduate students may leave with limited education in the CLP and CFD fields. ${ }^{27}$ Accordingly, this survey revealed a strong desire among South African MFOS for professional development and the need for a dedicated educational programme(s) in the CLP/CFD field.

CFD surgery programmes are available in different parts of the world as a subspecialty obtained by a clinical fellowship residency. ${ }^{29}$ Responses in this study show that 79.9\% recommended a fellowship and certificate programme. Concerning the length of such a programme, the respondents are equally divided between one or two years, which is partially in line with the minimum 12 months of fellowship residency recommended by Silvestre et al. ${ }^{30}$

Similar to the current recommended structure of fellowships in different parts of the world ${ }^{31,32}$, the majority of the respondents recommended that the training should place more emphasis on discussions and clinical contact, with evaluation by means of formal examinations and a clinical hours logbook.

The respondents agreed with the findings of other studies that participation in a multidisciplinary team is vital in order to produce surgeons who are capable of providing safe, efficient and effective care for those affected with CLP/CFD. ${ }^{29}$ Therefore, such comprehensive training can only be offered by a multidisciplinary centre where a high volume of craniofacial surgical procedures are performed by experts in the field. ${ }^{33}$

As stated by Egro et al. $^{34}$, candidate selection criteria should include professional degrees, the number of years qualified and possibly even an admission examination. But the respondents did not consider other requirements such as research experience and publications in candidate selection. This is in contrast with Grewal et al. ${ }^{35}$, who state that scientific publication is a good indicator of those who will be willing to provide fellowship mentoring and education. However, the respondents in this survey recommended that the selected candidates must have interest and passion and should be planning to join an established craniofacial team. These could be important factors in building much-needed educational capacity.

\section{CONCLUSION}

There is a need to establish an educational strategy for MFOS in CLP and CFD surgery to ensure they are competent and can, therefore, provide multidisciplinary services for CLP/CFD patients. This study revealed that many practitioners are enthusiastic about and willing to enrol in training programmes to prepare them to deliver the best clinical care in CLP/CFD management.

This study also provided information about candidate selection criteria, education objectives and evaluation of such programme(s). Our findings are that, to be able to offer such education programme(s) in South Africa, MFOS, academicians, practitioners and professional societies need to collaborate in order to maintain and develop craniofacial centres where a high volume of CLP/CFD surgical procedures are performed and where enough experts are employed.

All this will provide sufficient training for the candidate not only to be able to provide ideal and comprehensive services for CLP/CFD patients but also to undertake leadership positions in a multidisciplinary team.

\section{Acknowledgements}

The authors would like to thank the Gerald Gavron Research Fund of the South African Society of Orthodontics for financial support, SAS Olorunju PhD, the Biostatistics Unit of the South African Medical Research Council for providing the statistical support, and Professor FA de Wet, Professor Emeritus for proofreading the manuscript.

\section{Appendix 1}

The dataset supporting the conclusions of this article is not currently available, as it is part of the researcher's $\mathrm{PhD}$ thesis. The questionnaire used to collect the data is available from the corresponding author on request.

\section{Declaration}

This article is based on a study done by the researcher in partial fulfilment of his $\mathrm{PhD}$ thesis.

The authors declare no conflict of interest.

\section{Funding}

The PhD project was funded by the SA Society of Orthodontics Gerald Gavron Fund. The funding sources were not involved in the design of the study, data collection analysis, interpretation of results, or writing the manuscript.

\section{References}

1. Meara JG, Hagander L, Leather AJM. Surgery and global health: A Lancet commission: Lancet, London. 2014; 383 (9911): 12-3.

2. Taro T, Yao C, Ly S, Wipfli H, Magee K, Vanderburg R, et al. The global surgery partnership: An innovative partnership for education, research, and service. Acad Med. 2016; 91(1): 75-8

3. Poenaru D, Lin D, Corlew S. Economic valuation of the global burden of cleft disease averted by a large cleft charity. World J Surg. 2016; 40(5): 1053-9.

4. Sachs SA, Schwartz MH, Drew SJ. The oral and maxillofacial 'surgeon's role in the care of patients with cleft lip and palate deformities. NY State Dent J. 1998; 64(7): 24-9.

5. Brennan PA, Macey-Dare LV, Flood TR, Markus AF, Uppal R. Cleft lip and palate management by UK consultant oral and maxillofacial surgeons: A national survey. Cleft Palate Craniofac J. 2001; 38(1): 44-8.

6. Bütow $\mathrm{K}$, Zwahlen R. Ultimate result. Cleft ultimate treatment. $2^{\text {nd }}$ ed. Reach Publishers, Durban. 2016; 20, 423, 430. 
7. Rocha NS, Laureano Filho JR, Silva ED, Almeida RC. Perception of oral maxillofacial surgery by healthcare professionals. Int J Oral Maxillofac Surg. 2008; 37(1): 41-6.

8. Gadbury-Amyot CC, Simmer-Beck M, McCunniff M, Williams KB. Using a multifaceted approach including community-based service-learning to enrich formal ethics instruction in a dental school setting. J Dent Ed. 2006; 70(6): 652-61.

9. Lass NJ, Gasperini RM, Overberger JE, Connolly ME. The exposure of medical and dental students to the disorder of cleft palate. Cleft Palate J. 1973; 10(56): 306-11.

10. Spriestersbach DC, Dickson DR, Fraser FC, Horowitz SL, McWilliams BJ, Paradise JL, et al. Clinical research in cleft lip and cleft palate: The state of the art. Cleft Palate J. 1973; 10: 113-65.

11. Marks M. A teamwork approach to cleft palate rehabilitation in South Africa. S Afr J Commun Disord. 1960; 7(2): 8-10.

12. Bütow KW. Treatment of cleft lip and palate. Part V: The clinic and the multidisciplinary approach to cleft lip and palate cases. J Dent Assoc S Afr. 1984; 39(8): 543-5.

13. Berkowitz S. Cleft lip and palate: Diagnosis and management: Springer-Verlag; Berlin, 2013. 885.

14. Garner HG. Teamwork models and experience in education: Allyn \& Bacon; Needham Heights, MA 1995; 65.

15. McCarthy JG, editor. Development of craniofacial orthodontics as a subspecialty at New York University Medical Center. Semin Orthod. 2009; 15(4): 221-4.

16. Kern DE, Thomas PA, Hughes MT. Curriculum development for medical education: A six-step approach. $2^{\text {nd }}$ ed. Johns Hopkins University Press; Baltimore, MD 2009; 5-15.

17. Medpages, South Africa: (updated 7 Sep 2016; cited 28 July 2017). Available from: https://www.medpages.info/sf/index. php?page=services

18. Vallino LD, Lass NJ, Pannbacker M, Klaiman PG, Miller P. Medical students' knowledge of and exposure to cleft palate. Cleft Palate Craniofac J. 1992; 29(3): 275-8.

19. Modi N, Ross E. The current practices, training and concerns of a group of hospital-based speech therapists working in the area of dysphagia. S Afr J Commun Disord. 2000; 47: 3-14.

20. Snyman L, Visser J. The adoption of social media and social media marketing by dentists in South Africa. S Afr Dent $\mathrm{J}$. 2014; 69(6): 258-64

21. Kellerman SE, Herold J. Physician response to surveys. A review of the literature. Am J Prev Med. 2001; 20(1): 61-7.

22. Keating NL, Zaslavsky AM, Goldstein J, West DW, Ayanian JZ. Randomised trial of $\$ 20$ versus $\$ 50$ incentives to increase physician survey response rates. Med Care 2008; 46(8): 878-81.

23. Flanigan TS, McFarlane E, Cook S, editors. Conducting survey research among physicians and other medical professionals: A review of current literature. In Proceedings of the Survey Research Methods Section, American Statistical Association. May 15 2008; 1: 4136-47.

24. Modi, N, Ross E. The current practices, training and concerns of a group of hospital-based speech therapists working in the area of dysphagia. The South African Journal of communication disorders. 2000; 47: 3-14

25. Thandeka M, Penelope F, Robin J. Are South African speech-language therapists adequately equipped to assess English Additional Language (EAL) speakers who are from an indigenous linguistic and cultural background? A profile and exploration of the current situation. S Afr $\mathrm{J}$ Commun Disord. 2016; 63(1): e1-e5.

26. Noble J, Schroth RJ, Hechter FJ, Huminicki A, Wiltshire WA. Motivations of orthodontic residents in Canada and the United States to treat patients with craniofacial anomalies, cleft lip/palate, and special needs. Cleft Palate Craniofac J. 2012; 49(5): 596-600.
27. Bedwinek AP, Kummer AW, Rice GB, Grames LM. Current training and continuing education needs of preschool and school-based speech-language pathologists regarding children with cleft lip/palate. Lang Speech Hear Serv Sch. 2010; 41(4): 405-15.

28. Kuehn DP, Kummer AW, 'D'Antonio LL, Karnell MP. Cleft palate and speech: Three models of focused education. Perspect Speech Sci Orofac Disord. 2006; 16(2): 17-21.

29. Patel N, Dittakasem K, Fearon JA. Craniofacial fellowship training: Where are we now? Plast Reconstr Surg. 2015; 135(5): 1454-60.

30. Silvestre J, Agarwal D, Taylor JA. Craniofacial surgery fellowship websites. J Craniofac Surg. 2016; 27(4): 831-4.

31. Nissen $L$. The international association of oral \& maxillofacial surgery: An organisation of contrasts and similarities. J Maxillofac Oral Surg. 2010; 9(4): 322.

32. Denadai R. The Sobrapar Hospital Craniofacial Surgery Fellowship: Wide craniofacial surgery training based on historical and evolving principles. J Craniofac Surg. 2018; 29(7): 1686-8

33. Laskin DM. Learning to keep our teachers. J Oral Maxillofac Surg. 1991; 49(12): 1263

34. Egro FM, Blecher NA, Losee JE, Nguyen VT, Goldstein J. Craniofacial surgery fellowship selection criteria: A national program director survey. J Craniofac Surg. 2017; 28(5): 1132-5.

35. Grewal NS, Spoon DB, Kawamoto HK, Jones NF, Da Lio AL, Crisera $\mathrm{C}$, et al. Predictive factors in identifying subspecialty fellowship applicants who will have academic practices. Plast Reconstr Surg. 2008; 122(4): 1264-71. 